J Phys Chem B. 2018 April 12; 122(14): 3908-3919. doi:10.1021/acs.jpcb.8b01747.

\title{
Designing Well-Structured Cyclic Pentapeptides Based on Sequence-Structure Relationships
}

\author{
Diana P. Slough ${ }^{1, \ddagger}$, Sean M. McHugh ${ }^{1, \ddagger}$, Ashleigh E. Cummings ${ }^{1}$, Peng Dai ${ }^{2}$, Bradley L. \\ Pentelute $^{2}$, Joshua A. Kritzer ${ }^{1}$, and Yu -Shan Lin ${ }^{*}, 1$ \\ ${ }^{1}$ Department of Chemistry, Tufts University, Medford, Massachusetts 02155, USA \\ 2Department of Chemistry, Massachusetts Institute of Technology, Cambridge, Massachusetts \\ 02139, USA
}

\begin{abstract}
Cyclic peptides are a promising class of molecules for unique applications. Unfortunately, cyclic peptide design is severely limited by the difficulty in predicting the conformations they will adopt in solution. In this work, we use explicit-solvent molecular dynamics simulations to design wellstructured cyclic peptides by studying their sequence-structure relationships. Critical to our approach is an enhanced sampling method that exploits the essential transitional motions of cyclic peptides to efficiently sample their conformational space. We simulated a range of cyclic pentapeptides from all-glycine to a library of cyclo- $\left(\mathrm{X}_{1} \mathrm{X}_{2} \mathrm{AAA}\right)$ peptides to map their conformational space and determine cooperative effects of neighboring residues. By combining the results from all cyclo- $\left(\mathrm{X}_{1} \mathrm{X}_{2} \mathrm{AAA}\right)$ peptides, we developed a scoring function to predict the structural preferences for $\mathrm{X}_{1}-\mathrm{X}_{2}$ residues within cyclic pentapeptides. Using this scoring function, we designed a cyclic pentapeptide, cyclo-(GNSRV), predicted to be well structured in aqueous solution. Subsequent CD and NMR spectroscopy revealed that this cyclic pentapeptide is indeed well structured in water, with NOE and $J$-coupling values consistent with the predicted structure.
\end{abstract}

\section{Graphical Abstract}

\footnotetext{
"Corresponding Author: yu-shan.lin@tufts.edu.

¥Author Contributions

These authors contributed equally.

Notes

The authors declare no competing financial interests.

Supporting Information

The Supporting Information is available free of charge on the ACS Publications website.

Populations of 16 turn combinations from simulations of cyclo- $\left(\mathrm{X}_{1} \mathrm{X}_{2} \mathrm{AAA}\right)$; $1 \mathrm{H} 1 \mathrm{D}, 1 \mathrm{H}-1 \mathrm{H} 2 \mathrm{D}$ TOCSY and ${ }^{1} \mathrm{H}-{ }^{1} \mathrm{H}$ 2D ROESY NMR spectra of cyclo-(GNSRV) and cyclo-(GFDNV); comparison of ${ }^{1} \mathrm{H}$ 1D NMR spectra of cyclo-(GNSRV) and cyclo-(GFDNV) after 6 week incubation; thermodynamics decompositions for cyclo-(GGGGG) and cyclo-(AAAAA); populations and turn combinations for the top three most populated clusters of cyclo-( $\mathrm{X}_{1}$ AAAA) and cyclo-( $\left.\mathrm{X}_{1} \mathrm{X}_{2} \mathrm{AAA}\right)$; highest scoring sequences from neighbor analysis; thermodynamic decomposition for cyclo-(GNSRV) and five parent sequences; NOEs and $J$-coupling values for cyclo-(GNSRV) and cyclo-(GFDNV) (PDF)
} 


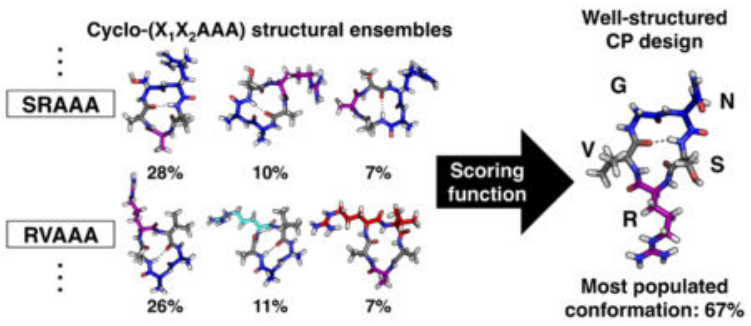

\section{INTRODUCTION}

Cyclic peptides (CPs) have promising applications in nanotechnology, ${ }^{1-3}$ as well as potential therapeutics, targeting a variety of protein-protein interactions (PPIs). ${ }^{4-12}$ PPIs play critical roles in important and disease-relevant biological processes. ${ }^{13,14}$ Modulating PPIs thus provides a means to control diverse cellular functions for both fundamental research and disease intervention. ${ }^{15,16}$ Despite the promise of CPs for these applications, de novo design of well-structured CPs in aqueous solution remains challenging. CPs tend to form multiple conformations in solution, ${ }^{17-28}$ making them difficult to design or even characterize. Furthermore, the limited availability of solution structural information makes it difficult to develop sequence-structure relationships for CPs. Currently, there is no tractable experimental method to synthesize and characterize the structural ensembles of hundreds of CPs to determine which CPs are well structured, and ultimately to understand how CP sequences control structures. ${ }^{29-32}$

While experimental determination of structural ensembles is difficult, there have been many promising contributions from computational simulations. ${ }^{33-51}$ Recently, we developed a novel, highly efficient enhanced sampling method custom-tailored to CPs by identifying their essential transitional motions (coupled two-dihedral angle movements) ${ }^{49}$ This enhanced sampling method has made it possible for us to quickly and efficiently sample a CP's structural ensemble, with the inclusion of explicit water. ${ }^{49-51}$ This platform produces more rapidly converged results, allowing us to simulate more systems than was previously possible. This advance has made it much more feasible to gather the broad simulation data needed to study sequence-structure relationships for CPs. In this work, we used this method to systematically simulate over 70 head-to-tail cyclized pentapeptides, uncovered their sequence-structure relationships and ultimately designed a well-structured $\mathrm{CP}$.

\section{MATERIALS AND METHODS}

\section{Model peptides}

The following model peptides were used in this study: cyclo-(GGGGG); cyclo-( $\left.\mathrm{X}_{1} \mathrm{AAAA}\right)$, where $X_{1}$ was any of the 20 natural amino acids; cyclo- $\left(X_{1} X_{2} A A A\right)$, where $X_{1} / X_{2}$ was $G$, A, V, F, R, D, N or S; cyclo-(GFSEV); cyclo-(GNSRV) and cyclo-(GFNDV). Two different initial structures of each CP, S1 and S2 (structure 1 and structure 2, respectively), were prepared using the Chimera molecular modeling package. ${ }^{52}$ To construct each $\mathrm{CP}$, the linear peptide was first built, followed by linkage of the $N$ - and $C$-terminal residues and subsequent energy minimization. 


\section{Bias-exchange metadynamics simulations}

Following preparation in Chimera, each initial structure was solvated using a preequilibrated box of water molecules. Minimal number of ions were added to neutralize the charge of the whole system. Each structure was then energy minimized using the steepest descent algorithm, followed by a four-step equilibration process. First, to allow the solvent molecules to equilibrate, a $50 \mathrm{ps}$ isochoric-isothermal ( $N V T$ ) simulation followed by a $50 \mathrm{ps}$ isobaric-isothermal (NPT) simulation were performed. In both simulations, a harmonic constraint was placed on the peptide heavy atoms, with a force constant of $1,000 \mathrm{~kJ} /$ $\mathrm{mol} \cdot \mathrm{nm}^{2}$. Subsequently, a $100 \mathrm{ps} N V T$ simulation followed by a $100 \mathrm{ps} N P T$ simulation were performed without any restraints, to equilibrate the entire system. A thermostat of 300 $\mathrm{K}$ and a barostat of $1 \mathrm{bar}$ were used for all equilibrations.

The $N P T$ ensemble was used for all BE-META production simulations. The temperature was maintained at $300 \mathrm{~K}$ using the V-rescale thermostat, ${ }^{53}$ with a time coupling constant of 0.1 ps. The $\mathrm{CP}$ and the solvent were coupled to two separate thermostats, in order to mitigate the "hot solvent-cold solute" problem. ${ }^{54,55}$ The pressure was maintained at 1 bar using the Berendsen barostat ${ }^{56}$ was used to maintain the pressure at 1 bar, with a time coupling constant of $2.0 \mathrm{ps}$ and an isothermal compressibility of $4.5 \times 10^{-5} \mathrm{bar}^{-1}$. All bonds involving hydrogen were constrained using the LINCS algorithm. ${ }^{57}$ Dynamics of the system were evolved using the leapfrog algorithm, ${ }^{58}$ with a time step of $2 \mathrm{fs}$. Both short-range LennardJones and electrostatic nonbonded interactions were truncated at $1.0 \mathrm{~nm}$. Beyond the cutoff distance, Particle Mesh Ewald (PME) ${ }^{59}$ was used for the electrostatic interactions, with a Fourier spacing of $0.12 \mathrm{~nm}$ and an interpolation order of 4 . A long-range dispersion correction $^{60}$ for the energy and pressure was used for the Lennard-Jones interaction beyond the cutoff. All trajectories were saved every 1 ps for subsequent analysis.

All simulations were performed using the RSFF2 force field ${ }^{61}$ with TIP3P water $^{62}$ in Gromacs 4.6.7 ${ }^{63}$ with the PLUMED 2 plugin. ${ }^{64}$ The RSFF2 force field was found to accurately recapitulate several CP crystal structures ${ }^{48}$ and therefore will be used throughout this work. Conformational sampling of all CPs was enhanced using BE-META simulations. The collective variables (CVs) in the BE-META simulations consist of two types of 2D biases. The first 2D bias is along $\phi_{i} \times \psi_{i}$, where $\phi / \psi$ are the backbone dihedral angles of the same residue. The second type of $2 \mathrm{D}$ bias is along $\psi$ of one residue and $\phi$ of the next residue, $\psi_{i} \times \phi_{i+1}$. These 2D biases were previously found to enhance the conformational sampling of CPs efficiently. ${ }^{49}$ Both types of the $2 \mathrm{D}$ biases are performed on each residue, giving a total of 10 biased replicas for a cyclic pentapeptide. Gaussian hills were deposited every $4 \mathrm{ps}$, with a height of $0.1 \mathrm{~kJ} / \mathrm{mol}$ and a width of $0.314 \mathrm{rad}$. Exchanges were attempted every 5 ps between different replicas. For analysis of an unbiased structural ensemble, five neutral replicas were added, giving a total of 15 replicas per CP.

\section{Principal component and cluster analysis}

To characterize the structural ensemble of each $\mathrm{CP}$, the last $50 \mathrm{~ns}$ of the unbiased replicas were analyzed using dihedral principal component analysis (dPCA) with the $\phi$ and $\psi$ angles of all residues ${ }^{65,66}$ However, if the peptide sequence is homogeneous (i.e. cyclo-(AAAAA)) an additional step needs to be performed prior to dPCA. To take degeneracy into account, 
the previously developed root-mean-square deviation (RMSD) scheme was applied. ${ }^{49}$ In brief, first the $\phi / \psi$ dihedral angles of the neutral replicas were calculated. For a cyclic pentapeptide with a homogeneous sequence there are five ways of reordering each frame. The RMSD to a reference structure was calculated for each of the five permutations, and the structure with the lowest RMSD to the reference structure was used to reorder the CP.

Following dPCA, the population of each cluster was calculated using a density peak-based cluster analysis. ${ }^{67}$ For cluster analysis, the principal subspace along the first three principal components (PC1, PC2 and PC3) was divided into $50 \times 50 \times 50$ grids. Only grids with a population greater than 0.1 were used in cluster analysis. The population of each cluster was determined by summing the population of every grid the cluster contained. APCA and cluster analysis was used to analyze the structural ensembles of cyclo-( $\left.\mathrm{X}_{1} \mathrm{AAAA}\right)$, cyclo-

( $\left.\mathrm{X}_{1} \mathrm{X}_{2} \mathrm{AAA}\right)$, cyclo-(GFSEV), cyclo-(GNSRV) and cyclo-(GFDNV).

Simulation convergence was monitored using the normalized integrated product (NIP) $)^{38}$ of the density profiles along PC1, PC2 and PC 3 of the $\mathrm{S} 1$ and $\mathrm{S} 2$ simulations. Convergence was achieved when the density profiles were similar. Final simulation lengths ranged from $100 \mathrm{~ns}$ to $300 \mathrm{~ns}$. All further analysis was performed on the S1 simulations.

\section{Cut-off turn analysis}

Due to their highly constrained nature, cyclic pentapeptides typically form structures containing a $\beta$-turn plus a tight turn on the opposite side of the CP. The four commonly observed $\beta$-turns and tight turns give a total of 16 turn combinations (Figure 1A). However, for cyclo-(GGGGG), dPCA and cluster analysis did not identify all 16 turn combinations. To determine whether all turn combinations were present in cyclo-(GGGGG), turns were identified if the $\phi / \psi$ dihedral angles were within $35^{\circ}$ of the ideal values for a specific type of turn (Figure 1A). Similarly, this cut-off based turn type analysis was used to compare all 16 types of turn combinations in the cyclo- $\left(\mathrm{X}_{1} \mathrm{AAAA}\right)$ and cyclo- $\left(\mathrm{X}_{1} \mathrm{X}_{2} \mathrm{AAA}\right)$ pentapeptides (Figures $3 \mathrm{~A}$ and $\mathrm{S} 1$ ), as the dPCA-cluster analysis was unable to pick up combinations with very low populations.

\section{Logo plot for individual amino acids from cyclo-( $X_{1}$ AAAA) simulations}

To determine the most probable amino acid for each position of a given turn combination, we weighted $\mathrm{X}_{1}$ in cyclo-( $\left.\mathrm{X}_{1} \mathrm{AAAA}\right)$ using the following scheme. The preference of the amino acid $X_{1}$, when $X_{1} \neq A$, for each of the five locations within a given turn combination was determined by its population from cut-off turn analysis. In the case of cyclo-(AAAAA), there are five degenerate amino acids, and the population was divided by five for the associated position in the logo plot. The logo plot for cyclo-( $\left.\mathrm{X}_{1} \mathrm{AAAA}\right)$ for the $\beta_{I I}{ }^{\prime}+\mathrm{a}_{\mathrm{R}}$ turn combination is shown in Figure 4A.

\section{Neighbor analysis for $X_{1} X_{2}$ from cyclo- $\left(X_{1} X_{2} A A A\right)$ simulations}

To help design well-structured cyclic peptides, a scoring function based on neighboring residues was developed using the simulation results of cyclo- $\left(\mathrm{X}_{1} \mathrm{X}_{2} \mathrm{AAA}\right)$, where $\mathrm{X}_{1} / \mathrm{X}_{2}$ is $\mathrm{G}, \mathrm{V}, \mathrm{F}, \mathrm{R}, \mathrm{D}, \mathrm{N}$ and $\mathrm{S}$. To evaluate the preference score for a sequence cyclo$\left(\mathrm{X}_{1} \mathrm{X}_{2} \mathrm{X}_{3} \mathrm{X}_{4} \mathrm{X}_{5}\right)$ to adopt a specific $\beta$-turn at $\mathrm{X}_{1} \mathrm{X}_{2}$ and a specific tight turn at $\mathrm{X}_{4}$, the 
sequence was broken down into five sets of nearest neighbor pairs $-X_{1} X_{2}, X_{2} X_{3}, X_{3} X_{4}$, $\mathrm{X}_{4} \mathrm{X}_{5}$ and $\mathrm{X}_{5} \mathrm{X}_{1}$, and the total preference score was the sum of the five populations for each pair to adopt the desired structure in the simulations of cyclo- $\left(\mathrm{X}_{1} \mathrm{X}_{2} \mathrm{AAA}\right)$, cyclo$\left(\mathrm{X}_{2} \mathrm{X}_{3} \mathrm{AAA}\right)$, etc. For example, the score for sequence cyclo- $\left(\mathrm{X}_{1} \mathrm{X}_{2} \mathrm{X}_{3} \mathrm{X}_{4} \mathrm{X}_{5}\right)$ adopting a type II' $\beta$-turn at $X_{1} X_{2}$ and an $\alpha_{R}$ turn at $X_{4}$ was calculated as follows. We analyzed the structural ensemble of cyclo- $\left(\mathrm{X}_{1} \mathrm{X}_{2} \mathrm{AAA}\right)$ using the cut-off based turn analysis to evaluate the population of cyclo- $\left(\mathrm{X}_{1} \mathrm{X}_{2} \mathrm{AAA}\right)$ that adopts a type $\mathrm{II}^{\prime} \beta$-turn at $\mathrm{X}_{1} \mathrm{X}_{2}$ and an $\mathrm{a}_{\mathrm{R}}$ turn at $\mathrm{A}^{4}$, the population of cyclo- $\left(\mathrm{AX}_{2} \mathrm{X}_{3} \mathrm{AA}\right)$ that adopts a type II' $\beta$-turn at ${ }^{1} \mathrm{AX}{ }^{2}$ and an $\mathrm{a}_{\mathrm{R}}$ turn at $\mathrm{A}^{4}$, the population of cyclo- $\left(\mathrm{AAX}_{3} \mathrm{X}_{4} \mathrm{~A}\right)$ that adopts a type $\mathrm{II}^{\prime} \beta$-turn at ${ }^{1} \mathrm{AA}^{2}$ and an $a_{R}$ turn at $X^{4}$, etc. The score was then calculated as the sum of these five populations, when each pair is located at the desired location of the target turn combination (example for cyclo(GNSRV) shown in Figure 5A).

\section{Thermodynamics decomposition}

To further understand the structural ensemble of a $\mathrm{CP}$, we performed thermodynamics decomposition of the $\mathrm{S} 1$ simulation. $\Delta G$ between clusters was calculated using the Boltzmann equation, using the ratios of cluster populations and the most populated cluster as a reference. $\Delta G$ was then further separated into $\Delta H$ and $\Delta S$, where $\Delta H$ was estimated from the difference in potential energy between clusters. $\Delta H$ was then further decomposed into peptide in vacuum ( $\Delta H_{\mathrm{P}}^{\mathrm{vac}}$ ) and the rest $\left(\Delta H_{\text {rest }}\right)$. To perform this decomposition, the potential energy of two groups was calculated: peptide and solvent/ions (note that ions may not be present in all systems). The peptide enthalpy ( $\left.\Delta H_{\mathrm{P}}^{\mathrm{vac}}\right)$ consisted of peptide LennardJones $\left(\Delta H_{\mathrm{P}}^{\mathrm{LJ}}\right)$, short-range and 1,4 electrostatics $\left(\Delta H_{\mathrm{P}}^{\mathrm{EE}(\mathrm{SR}+1,4)}\right)$, bonds $\left(\Delta H_{\mathrm{P}}^{\text {bond }}\right)$, angles ( $\Delta H_{\mathrm{P}}^{\text {angle }}$ ), proper dihedrals ( $\Delta H_{\mathrm{P}}^{\text {dih. }}$ ) and improper dihedrals ( $\Delta H_{\mathrm{P}}^{\text {imp. }}$ ). $\Delta S$ was further decomposed into configurational entropy of the peptide ( $\Delta S_{\mathrm{P}}^{\text {conf }}$ ) and solvation entropy $\left(\Delta S_{\mathrm{w}}\right) . \Delta S_{\mathrm{P}}^{\mathrm{conf}}$ was calculated using the maximum information spanning tree (MIST) ${ }^{68-70}$ method and $\Delta S_{\mathrm{w}}$ was calculated using $\Delta S_{\mathrm{w}}=\Delta S-\Delta S_{\mathrm{P}}^{\text {conf }}$.

\section{Linear peptide synthesis}

The linear peptide was synthesized at $0.04 \mathrm{mmol}$ scale on HMPB-ChemMatrix resin (PCAS BioMatrix Inc., loading $=0.5 \mathrm{mmol} / \mathrm{g}$ ). The linear peptides was prepared with C-terminal glycine to facilitate head-to-tail cyclization. The HMPB resin was firstly functionalized with glycine: $5 \mathrm{mmol}$ Fmoc-glycine-OH and $2.5 \mathrm{mmol} N, N^{\prime}$-diisopropylcarbodiimide (DIC) were dissolved in $15 \mathrm{~mL}$ dimethylformamide (DMF). After 10 minutes at room temperature, the mixture was added to $0.75 \mathrm{~g}$ HMPB resin in a $20-\mathrm{mL}$ Torviq fritted syringe. After another 1 minute, $0.05 \mathrm{mmol}$ 4-dimethylaminopyridine (DMAP) was added and reacted at room temperature for 16 hours, followed by 3 times wash with DMF, twice 5 min deprotection with $20 \%(\mathrm{v} / \mathrm{v})$ piperidine in DMF and 4 times wash with DMF. The resin was washed thoroughly with dichloromethane (DCM) and dried under vacuum. Following solidphase peptide synthesis (SPPS) was carried out on a synthesizer for automated flow peptide synthesis (AFPS). ${ }^{71}$ After completion of the SPPS, the resin was washed thoroughly with DCM and dried under vacuum. The resins were transferred to a $50-\mathrm{mL}$ plastic tube and the 
peptide was simultaneously cleaved from the resin and side-chain deprotected by treatment with $2.5 \%(\mathrm{v} / \mathrm{v})$ water, $2.5 \%(\mathrm{v} / \mathrm{v}) 1,2$-ethanedithiol (EDT), and 1\% (v/v) triisoproprylsilane in neat trifluoroacetic acid (TFA) for 2 hours at room temperature. The resulting solution containing peptide was triturated and washed with cold diethyl ether (pre-chilled in $-80^{\circ} \mathrm{C}$ freezer) two times. The obtained gummy-like solid was dissolved in $50 \% \mathrm{H}_{2} \mathrm{O}: 50 \%$ acetonitrile containing $0.1 \%$ TFA and lyophilized.

\section{Peptide cyclization and purification}

The lyophilized crude peptide was directly used for cyclization. Cyclization condition: 0.5 $\mathrm{mM}$ peptide, $1.5 \mathrm{mM}$ 1-[bis(dimethylamino)methylene]-1H-1,2,3-triazolo[4,5-b]pyridinium

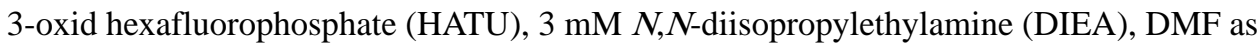
solvent, room temperature for 1 hour. The cyclization reaction was quenched by adding TFA. After removing solvents by rotary evaporator, the reaction mixture was re-dissolved in water containing 10\% dimethyl sulfoxide (DMSO) and purified on Agilent 1260 Infinity Automated LC/MS Purification System, with a semi- preparative Reverse Phase-HPLC column (Agilent Zorbax 300SB C 3 column: $21.2 \times 250 \mathrm{~mm}, 7 \mu \mathrm{m}$, linear gradient: 1-41\% B over $80 \mathrm{~min}$, flow rate: $4 \mathrm{~mL} / \mathrm{min}$ ). The purity of fractions was confirmed by LC-MS analysis. The fractions containing pure cyclized peptide were combined and lyophilized to yield cyclized peptide powder.

\section{NMR characterization}

The peptide was dissolved in $\mathrm{H}_{2} \mathrm{O}: \mathrm{D}_{2} \mathrm{O}(90: 10)$ at a concentration of roughly $3.5 \mathrm{mM}$. 1D and 2D ${ }^{1} \mathrm{H}$ NMR spectra were recorded on a Bruker $600 \mathrm{MHz}$ spectrometer with CryoProbe at $288 \mathrm{~K}$. Complete resonance assignments were made using homonuclear ${ }^{1} \mathrm{H}-{ }^{1} \mathrm{H}$ TOCSY and ROESY experiments. Standard pulse programs available from the Bruker library were used, with mixing times of $60 \mathrm{~ms}$ for the TOCSY and $250 \mathrm{~ms}$ for the ROESY. ${ }^{1} \mathrm{H}$ chemical shifts were referenced to DSS ( $\delta 0.00 \mathrm{ppm}$ ) in water. ${ }^{3}{ }_{\mathrm{NH}}, C_{\mathrm{Ha}}$ coupling constants were measured from $1 \mathrm{D}^{1} \mathrm{H}$ NMR.

\section{CD characterization}

Compounds were dissolved in water to concentrations of $87.5 \mu \mathrm{M}$ as measured by peptide weight. Equal concentrations of the peptides were verified prior to $\mathrm{CD}$ analysis by subjecting peptides to analytical HPLC and normalizing based on peak volumes. CD spectra were obtained on a Jasco J-815 CD Spectrometer at $20^{\circ} \mathrm{C}$ using the following measurement parameters: wavelength range 190-260 nm; step resolution, $0.5 \mathrm{~nm}$; speed, $20 \mathrm{~nm} / \mathrm{min}$; accumulations, 3; response, $1 \mathrm{sec}$; bandwidth, $1 \mathrm{~nm}$; path length, $0.1 \mathrm{~cm}$.

\section{RESULTS AND DISCUSSION}

\section{Structural ensembles of cyclo-(GGGGG) and cyclo-(AAAAA) map out the available conformational space for simple cyclic pentapeptides}

Cyclic pentapeptides typically form a $\beta$-turn plus a tight turn opposite the $\beta$-turn. ${ }^{72-79}$ There are four types of $\beta$-turns $\left(\beta_{\mathrm{I}}, \beta_{\mathrm{II}}, \beta_{\mathrm{I}^{\prime}}\right.$, and $\left.\beta_{\mathrm{II}}\right)$ and four types of tight turns $\left(\gamma, \gamma^{\prime}, \alpha_{\mathrm{R}}\right.$ and $a_{\mathrm{L}}$ ) that are commonly observed (Figure $1 \mathrm{~A}$ ), leading to 16 possible turn combinations for cyclic pentapeptides. A cyclic pentapeptide with a $\beta$-turn and a tight turn of $\gamma$ or inverse- $\gamma$ 
$\left(\gamma^{\prime}\right)$ tend to form two intra-peptide hydrogen bonds (Figure 1B, bottom row), while a cyclic pentapeptide having a $\beta$-turn and a tight turn with a dihedral angle of a right-handed or lefthanded $a$-helix ( $a_{R}$ and $a_{L}$, respectively) will form only one intra-peptide hydrogen bond (at the $\beta$-turn site; Figure 1B, top row). All these 16 turn combinations were seen in our bias-exchange metadynamics (BE-META) simulations of cyclo-(GGGGG) and are shown in Figure 1B. The most populated conformation was a $\beta_{\mathrm{II}}+\alpha_{\mathrm{L}}$, with a population of 14.7 $\pm 0.6 \%$. We observed that the mirror-image turn combination, $\beta_{I I}{ }^{\prime}+a_{R}$, has a similar population $(14.3 \pm 0.4 \%)$ as $\beta_{\mathrm{II}}+\mathrm{a}_{\mathrm{L}}$. Since glycine is achiral, theoretically, conformations that are mirror images of each other should have exactly the same population. In our simulations of cyclo-(GGGGG), each conformation and its mirror image indeed had similar populations (Figure 1B), further supporting convergence of our simulation results.

Among the 16 turn combinations observed in cyclo-(GGGGG), all clusters with an $a_{R} / a_{L}$ turn (top row of Figure 1B) were more populated than clusters with a $\gamma / \gamma^{\prime}$ turn (bottom row of Figure 1B). To further understand this structural preference of cyclo-(GGGGG), we performed thermodynamics decomposition on the 16 clusters (Table S1). The thermodynamics of clusters 1 and 2 were almost identical, which is consistent with the fact that they are mirror images of each other $\left(\beta_{I I}+a_{L}\right.$ vs. $\left.\beta_{I I}+a_{R}\right)$. The third and fourth most populated clusters, $\beta_{I}+\alpha_{R}$ and $\beta_{I^{\prime}}+\alpha_{L}$, had more favorable solvation enthalpy compared to the most populated clusters. However, they both had an unfavorable peptide enthalpy relative to the top clusters (most populated clusters; $\beta_{\mathrm{II}}+\mathrm{a}_{\mathrm{L}}$ and $\beta_{\mathrm{II}}{ }^{\prime}+\mathrm{a}_{\mathrm{R}}$ ), arising from unfavorable electrostatics, angles and dihedrals. Clusters 5 and 6 formed the $\beta_{I I}{ }^{\prime}+\alpha_{L}$ and $\beta_{I I}+a_{R}$ turn combinations, respectively, and were less stable than the most populated clusters due to peptide electrostatics and dihedrals. The least populated turn combinations involving $\alpha_{L}$ and $a_{R}, \beta_{I^{\prime}}+a_{R}$ and $\beta_{I}+a_{L}$ (clusters 7 and 8 ) had unfavorable peptide angles and dihedrals compared to the most populated cluster.

In contrast to clusters $1-8$, clusters $9-16$ formed a $\gamma / \gamma^{\prime}$ turn instead of adopting an $a_{R} / a_{L}$ conformation. Since clusters with a $\gamma / \gamma^{\prime}$ turn form two intra-peptide hydrogen bonds, their peptide electrostatics were more favorable than the most populated cluster (Table S1). However, clusters with a $\gamma / \gamma^{\prime}$ turn all had unfavorable angles and dihedrals as well as unfavorable solvation enthalpy, relative to the top cluster. A combination of these factors makes clusters with $\gamma / \gamma^{\prime}$ turns have lower populations than their $a_{R} / a_{L}$ counterparts.

Moving from achiral glycine to the simplest all L-amino acid peptide, cyclo-(AAAAA), we expected turn combinations involving an $a_{R}$ turn to be preferred over an $a_{L}$ turn, based on the $\phi$ angle preferences for an L-amino acid. The four most populated clusters of cyclo(AAAAA) from our BE-META simulation are shown in Figure 2, and indeed all these turn combinations had a tight $a_{\mathrm{R}}$ turn rather than a tight $a_{\mathrm{L}}$ turn, corresponding to clusters 2, 3, 6 , and 7 in Figure 1B for cyclo-(GGGGG). Similar to cyclo-(GGGGG), $\beta_{I I^{\prime}}+a_{R}$ was the most favorable turn combination, with a population of $52.9 \pm 0.7 \%$. The second most populated cluster formed a distorted type $\beta_{\mathrm{I}}+\mathrm{a}_{\mathrm{R}}$, where the distorted type I $\beta$-turn had nearly ideal dihedral angles for a type I $\beta$-turn, but deviation in the $\psi$ angle of the $i+2$ residue results in a turn that does not frequently hydrogen bond. 
Breaking down the thermodynamics of cyclo-(AAAAA), the distorted $\beta_{\mathrm{I}}+\mathrm{a}_{\mathrm{R}}$ cluster had less favorable electrostatics and dihedrals compared to the most populated $\beta_{I I}+a_{R}$ turn combination (Table S2). The third and fourth most populated clusters formed a $\beta_{I I}+a_{R}$ and a distorted type $\beta_{I^{\prime}}+a_{R}$, and compared to cyclo-(GGGGG), the preferred order of all the $a_{R^{-}}$ containing clusters remained the same. Both clusters 3 and 4 were less favorable than the most populated cluster due to entropy, specifically peptide configurational entropy. Looking at the peptide contribution to the thermodynamics, clusters 3 and 4 have poor electrostatics and cluster 4 (distorted $\beta_{I^{\prime}}+a_{R}$ ) also had unfavorable angles compared to the most populated $\beta_{I I}+a_{R}($ Table S2).

Overall, for the thermodynamics of cyclo-(GGGGG), we found that the most populated conformation, and its mirror-image counterpart, are stabilized over the other clusters via either peptide or solvation enthalpy. The most populated conformation of cyclo-(AAAAA), on the other hand, is entropically more favorable than the other clusters due to either configurational or solvation entropy. The complex balance between peptide enthalpy, solvation enthalpy and entropy for these two simple cyclic pentapeptide systems reaffirms the necessity of using explicit water in $\mathrm{CP}$ simulations to accurately describe each thermodynamic factor.

\section{Structural ensembles of cyclo-(XAAAA) show structural preferences of each amino acid}

To understand how different amino acids affect structural preferences of a cyclic pentapeptide, we performed BE-META simulations of cyclo-( $\left.\mathrm{X}_{1} \mathrm{AAAA}\right)$, where $\mathrm{X}_{1}$ was any of the 20 basic amino acids. The population and turn combination of the three most populated clusters for each of these 20 sequences are given in Table S3. We found that the turn combination $\beta_{\mathrm{II}}{ }^{\prime}+\mathrm{a}_{\mathrm{R}}$ was by far the most prevalent, accounting for $\sim 75 \%$ of all the turn combinations that form for these 20 CPs (Figure 3A). The second most populated turn combination was a distorted $\beta_{\mathrm{I}}+\mathrm{a}_{\mathrm{R}}(\sim 14 \%)$. Although $\beta_{\mathrm{II}^{\prime}}+\mathrm{a}_{\mathrm{R}}$ predominated among the turn combinations observed for these $20 \mathrm{CPs}$, the locations of the type II $\beta$-turn and the $a_{R}$ residue varied within the $\mathrm{X}_{1} \mathrm{AAAA}$ sequence (Figure $3 \mathrm{~B}$ and Table $\mathrm{S} 3$ ).

By combining the results from all 20 cyclo-( $\left.\mathrm{X}_{1} \mathrm{AAAA}\right) \mathrm{CPs}$, we constructed a logo plot showing the probability of each amino acid for each location in the $\beta_{I I}+\alpha_{R}$ turn combination (Figure 4A). We hypothesized that combining the most probable amino acid at every position of the $\beta_{I I}{ }^{\prime}+a_{R}$-structured cyclic pentapeptide would produce a sequence that adopts a well-structured conformation. Based on the results shown in Figure 4A, the sequence, cyclo-(GFSEV), was predicted to be the most structured for a $\beta_{I I^{\prime}}+\alpha_{R}$ turn combination, with the $\beta_{\mathrm{II}}$ turn located at ${ }^{1} \mathrm{GF}^{2}$ and $\mathrm{a}_{\mathrm{R}}$ turn located at $\mathrm{E}^{4}$. To verify this prediction, this designed sequence was simulated using BE-META simulations to characterize its structural ensemble. The most populated cluster (55\%) of cyclo-(GFSEV) was indeed the $\beta_{\mathrm{II}}{ }^{\prime}+\mathrm{a}_{\mathrm{R}}$ turn combination, with the type $\mathrm{II}^{\prime} \beta$-turn at ${ }^{1} \mathrm{GF}^{2}$ and a tight $\mathrm{a}_{\mathrm{R}}$ turn at $\mathrm{E}^{4}$ (Figure $4 \mathrm{~B}$ ). However, this population ( 55\%) was not significantly higher than the most populated cluster of simple cyclo-(AAAAA) $(\sim 53 \%)$. This result suggests that the structural preferences for each of the 20 amino acids within cyclo-( $\mathrm{X}_{1}$ AAAA) are not necessarily additive, implying that neighboring residues might affect each other's structural 
preferences. This would explain why merely using results from cyclo-( $\left.\mathrm{X}_{1} \mathrm{AAAA}\right)$ studies was unable to design a particularly well-structured cyclic pentapeptide.

\section{Structural ensembles of cyclo-( $\left.X_{1} X_{2} A A A\right)$ reveal cooperative effects between neighboring amino acids}

To understand the effects of neighboring amino acids on the structural ensemble of a cyclic pentapeptide, we performed BE-META simulations of cyclo-( $\left.\mathrm{X}_{1} \mathrm{X}_{2} \mathrm{AAA}\right)$, where $\mathrm{X}_{1} / \mathrm{X}_{2}$ was $\mathrm{G}, \mathrm{A}, \mathrm{V}, \mathrm{F}, \mathrm{R}, \mathrm{D}, \mathrm{N}$ or $\mathrm{S}$. These eight amino acids were chosen as a representative subsection of the 20 basic amino acids. The populations and turn combinations of the three most populated clusters for each of these 56 sequences is given in Table S4. Similar to cyclo( $\mathrm{X}_{1}$ AAAA), most of the top clusters formed a tight $\mathrm{a}_{\mathrm{R}}$ turn, which is consistent with the $\phi$ angle preferences for an L-amino acid. However, there were a few instances where a $\gamma$ turn occurs in the top three clusters. Nonetheless, we observed that $\beta_{I I}{ }^{\prime}+a_{R}$ remains the most prevalent in all 56 cyclo- $\left(\mathrm{X}_{1} \mathrm{X}_{2} \mathrm{AAA}\right) \mathrm{CPs}$, similar to cyclo-( $\left.\mathrm{X}_{1} \mathrm{AAAA}\right)$ (Figure $\mathrm{S} 1$ compared to Figure 3A). In fact, $\beta_{I^{\prime}}+a_{R}$ was the most populated cluster for 49 out of the 56 sequences. However, turn locations varied in the top clusters forming $\beta_{I I}{ }^{\prime}+a_{R}$, depending on their sequences.

\section{Rational design of well-structured CPs}

To help design a well-structured cyclic pentapeptide, we used the structural ensemble results of cyclo-( $\left.\mathrm{X}_{1} \mathrm{X}_{2} \mathrm{AAA}\right) \mathrm{CPs}$ to develop a scoring function based on the observed populations for the desired conformation. The scoring function combined the structural preferences of each neighboring pair $\left(X_{1} X_{2}, X_{2} X_{3}\right.$, etc. $)$ in a cyclic pentapeptide cyclo- $\left(X_{1} X_{2} X_{3} X_{4} X_{5}\right)$ for a specific conformation (see "Neighbor analysis for $\mathrm{X}_{1} \mathrm{X}_{2}$ in cyclo- $\left(\mathrm{X}_{1} \mathrm{X}_{2} \mathrm{AAA}\right)$ " in Materials and Methods in the SI). Since alanine was a common filler amino acid in the cyclo- $\left(\mathrm{X}_{1} \mathrm{X}_{2} \mathrm{AAA}\right)$ data set, we first ignored $\mathrm{A}$ and only analyzed structural preferences and developed scoring functions for $\mathrm{X}_{1} \mathrm{X}_{2}$ pairs, where $\mathrm{X}_{1} / \mathrm{X}_{2}$ was $\mathrm{G}, \mathrm{V}, \mathrm{F}, \mathrm{R}, \mathrm{D}, \mathrm{N}$ or $\mathrm{S}$. The sequences and scores for the 20 highest-scoring cyclo- $\left(\mathrm{X}_{1} \mathrm{X}_{2} \mathrm{X}_{3} \mathrm{X}_{4} \mathrm{X}_{5}\right)$ sequences for the $\beta_{\mathrm{II}}$ $+a_{R}$ turn combination, with a type II' $\beta$-turn at $X_{1} X_{2}$ and an $a_{R}$ turn at $X_{4}$, are given in Table S5. Of all 16,807 sequences, cyclo-(GNSRV) received the highest score (1.287) for the $\beta_{I I}{ }^{\prime}+a_{R}$ turn combination (Figure 5A and highlighted in blue in Figure 5B). To verify this prediction, BE-META simulations of cyclo-(GNSRV) were performed. The simulation results revealed a well-structured conformational ensemble, with the most populated cluster forming a type $\mathrm{II}^{\prime} \beta$-turn at ${ }^{1} \mathrm{GN}^{2}$ and a tight $\alpha_{\mathrm{R}}$ turn at $\mathrm{R}^{4}$, as predicted by the scoring function, with a population of $67 \%$ (Figure 6A).

To further understand why cyclo-(GNSRV) is well-structured, we performed thermodynamics decomposition on this peptide and on the five parent cyclo-( $\left.\mathrm{X}_{1} \mathrm{X}_{2} \mathrm{AAA}\right)$ peptides that contain the five relevant neighbor pairs (Table S6). Comparing the location of the turns in cyclo-(GNSRV) to the locations of the turns in the five parent sequences, cyclo(GNAAA), cyclo-(AAARV) and cyclo-(GAAAV) all had the $\beta_{I^{\prime}}+\alpha_{R}$ turns at the same location as cyclo-(GNSRV) in the most populated cluster. However, in cyclo-(ANSAA) and cyclo-(AASRA), the $\beta_{I I}{ }^{\prime}+a_{R}$ turn combination corresponding to cyclo-(GNSRV) occurred as the third and second most populated clusters, respectively. The comparison of the thermodynamics of cyclo-(GNSRV) and the five parent sequences shows that a variety of 
factors stabilized the most populated clusters, and that these factors are generally consistent among the five neighbor-pair peptides and cyclo-(GNSRV). For example, the most populated cluster of cyclo-(GNSRV), cyclo-(AAARV) and cyclo-(GAAAV) formed a $\beta_{\text {II }^{\prime}}$ $+a_{R}$, while the second most populated cluster formed a $\beta_{I I}{ }^{\prime}+\gamma$ with the $\gamma$ turn is at the same residues as the $a_{\mathrm{R}}$ turn. In all three simulations, the top clusters were stabilized over the second clusters due to enthalpy. Specifically, even though the $\beta_{\mathrm{II}^{\prime}}+\gamma$ clusters have more favorable intra-peptide electrostatics, they have more unfavorable dihedrals and much more unfavorable solvation enthalpy as compared to the most populated cluster. Interestingly, the most populated conformation of cyclo-(GNSRV) is both enthalpically and entropically stabilized over clusters 2 and 3 . This is unlike any of the other five parent sequences, whose most populated cluster is stabilized by either enthalpy or entropy alone.

Previously, using the simulation results of cyclo-( $\mathrm{X}_{1}$ AAAA), where $\mathrm{X}_{1}$ was any of the 20 basic amino acids, cyclo-(GFSEV) was predicted to have the highest preference for the $\beta_{\text {II' }}$ $+a_{R}$ turn combination. However, BE-META simulations of cyclo-(GFSEV) showed that the population of the desired structure $\left(\beta_{I^{\prime}}+a_{R}\right)$ was only $55 \%$, a modest improvement from the $53 \%$ in cyclo- (AAAAA). Indeed, when using the scoring functions derived from the cyclo$\left(\mathrm{X}_{1} \mathrm{X}_{2} \mathrm{AAA}\right)$ simulations results, the score for the $\beta_{\mathrm{II}}{ }^{\prime}+\mathrm{a}_{\mathrm{R}}$ conformation for cyclo-(GFSDV), the proxy of cyclo-(GFSEV) since in the cyclo- $\left(\mathrm{X}_{1} \mathrm{X}_{2} \mathrm{AAA}\right)$ data set $\mathrm{X}_{1} / \mathrm{X}_{2}$ could only be $\mathrm{G}$, $\mathrm{V}, \mathrm{F}, \mathrm{R}, \mathrm{D}, \mathrm{N}$ or S, ranked poorly at number 277 , with a score of 1.051 (highlighted in red in Figure 5B). This observation verified the importance of incorporating the neighboring effects in scoring the cyclic peptide's structural preference.

\section{The predicted II' $+a_{R}$ structure of cyclo-(GNSRV) is supported by NMR}

To corroborate our simulation predictions, we synthesized cyclo-(GNSRV) and characterized its structure in aqueous solution. NMR spectroscopy provided high-resolution data describing the structural ensemble of cyclo-(GNSRV) in water. The 1D spectrum and 2D spectra from ROESY and TOCSY experiments provided ample evidence that cyclo(GNSRV) was well structured in water (Figures S2-S5), and these data were wholly consistent with the predicted type II' $\beta$-turn at ${ }^{1} \mathrm{GN}^{2}$ and $\mathrm{a}_{\mathrm{R}}$ turn at $\mathrm{R}^{4}$ (Table S7-S8). Overall, protons had unique, well-resolved and well-dispersed chemical shifts, consistent with a single predominant structure. We observed several NOEs that support the predicted $\beta_{I I}{ }^{\prime}+a_{R}$ structure. For example, for types I and $I^{\prime} \beta$-turns, the distance between the $H_{N}$ protons of the $i+1$ and $i+2$ residues and the distance between the $\mathrm{H}_{\mathrm{N}}$ protons of the $i+2$ and $i$ +3 residues are both small $(<3 \AA)$; on the other hand, in types II and II' $^{\prime} \beta$-turns, only the distance between the $\mathrm{H}_{\mathrm{N}}$ protons of the $i+2$ and $i+3$ residues is small $(<3 \AA$ ) (Figure $1 \mathrm{~A})$. In the ROESY spectra of cyclo-(GNSRV) we observed a strong NOE between $\operatorname{Asn}^{2}\left(\mathrm{H}_{\mathrm{N}}\right)$ and $\operatorname{Ser}^{3}\left(\mathrm{H}_{\mathrm{N}}\right)$, but no NOE was observed between Gly1 $\left(\mathrm{H}_{\mathrm{N}}\right)$ and Asn2 $\left(\mathrm{H}_{\mathrm{N}}\right)$ (Figure 7A; Figure S6; Table S7). The presence of this specific $\mathrm{H}_{\mathrm{N}}-\mathrm{H}_{\mathrm{N}} \mathrm{NOE}$ and the lack of the other provides strong support for a type II or II' $\beta$-turn at residues ${ }^{1} \mathrm{GN}^{2}$, rather than a type I or I' $\beta$-turn. Similarly, the distance between the $\mathrm{H}_{\mathrm{N}}$ protons of the $i+1$ and $i+2$ residues is only small in a $a_{R}$ or $a_{L}$ turn, but not in a $\gamma$ or $\gamma^{\prime}$ turn (Figure 1A). We observed a strong NOE between $\operatorname{Arg}^{4}\left(\mathrm{H}_{\mathrm{N}}\right)$ and Val5 $\left(\mathrm{H}_{\mathrm{N}}\right)$ (Figure S6; Table S7), which supports a $\mathrm{a}_{\mathrm{R}}$ turn centered at $\operatorname{Arg} 4$. $J$-values allowed estimation of the $\phi$ angle for $\mathrm{Arg}^{4}$ at $-60 \pm 30^{\circ}$ (Figure S6; Table S8), which is consistent with an $a_{R}$ turn rather than an $a_{L}$ turn. Similarly, the $\phi$ angles for $\operatorname{Ser}^{3}$ 
and $\mathrm{Val}^{5}$ were estimated at $-120 \pm 30^{\circ}$ based on the $J$-values, which are also in agreement with the predicted structure (Figure 6A; Figure S6 and Table S8).

\section{Design of an unstructured control for cyclo-(GNSRV)}

We observed that one of the parent sequences of the well-structured cyclo-(GNSRV), cyclo(VGAAA), adopted a relatively structured $\beta_{\mathrm{II}}{ }^{\prime}+\mathrm{a}_{\mathrm{R}}$ configuration (58\%; Table S4), suggesting that it might be possible that any cyclic pentapeptide containing the VG motif would have a rather strong preference for the $\beta_{\mathrm{II}}{ }^{\prime}+\mathrm{a}_{\mathrm{R}}$ configuration regardless of the rest of the sequence. To test this hypothesis, based on our scoring function, we designed a negative control, cyclo-(GFDNV) (highlighted in red in Figure 5B), which contained the VG motif but had a low score for the $\beta_{I I^{\prime}}+a_{R}$ configuration. BE-META simulations showed that although the most populated cluster of cyclo-(GFDNV) still adopted a type II $^{\prime} \beta$-turn at residues ${ }^{1} \mathrm{GF}^{2}$ and an $\mathrm{a}_{\mathrm{R}}$ turn at $\mathrm{N}^{4}$, its population was, however, a mere $14.7 \%$ (Figure $6 \mathrm{~B}$ ).

To corroborate the simulation results of our negative control, we synthesized and characterized cyclo-(GFDNV) using NMR spectroscopy (Figures S7-S10; Tables S9-S10). Overall, specific NOEs and $J$-values consistent with a single predominant structure, as observed for cyclo-(GNSRV), were not observed for cyclo-(GFDNV). For instance, instead of a distinct, selective pattern of $\mathrm{H}_{\mathrm{N}}-\mathrm{H}_{\mathrm{N}}$ NOEs, we observed four out of the five possible $\mathrm{H}_{\mathrm{N}}-\mathrm{H}_{\mathrm{N}}$ NOEs (Figure 7B; Table S9). This indicates that no one single structure predominates in solution, but that multiple different structures with various underlying turn combinations are present. Also, $J$-values allowed estimation of $\phi$ angles for $\mathrm{Asp}^{3}$ and $\mathrm{Val}^{5}$. Both of these values were estimated at $-120 \pm 30^{\circ}$, which was not consistent with an a-turn at either residue (Table S10). Finally, we observed an additional set of peaks within the NMR spectrum of cyclo-(GFDNV) that integrated to roughly 33\% of the total peak volume (Figure S11). These are consistent with the presence of two or more conformations within the ensemble that are stable on the NMR timescale. This is another clear indicator that this peptide does not have a single predominant structure in aqueous solution.

CD spectroscopy is complementary to NMR and provides a low-resolution but informative measurement of the extent of peptide structure in solution. As shown in Figure 7C, the CD spectra of cyclo-(GNSRV) and cyclo-(GFDNV) show broad minima between 208 and 218 $\mathrm{nm}$, consistent with mixed $\alpha$-helical and $\beta$-sheet structures. The negative ellipticity from cyclo-(GNSRV) is roughly fourfold more intense than that of cyclo-(GFDNV). Though it is difficult to calculate the degree of structure accurately from $\mathrm{CD}$ data for cyclic peptides this small, these data do indicate a much higher degree of structure for cyclo-(GNSRV) compared to cyclo-(GFDNV).

\section{CONCLUSIONS}

In summary, using an efficient enhanced sampling method tailored for CPs, we characterized the structural ensembles of more than 70 head-to-tail cyclized pentapeptides. We demonstrated the value of these data by using them to rationally design a $\mathrm{CP}$ with a high degree of structure in water. We note that although this designed CP sequence is well structured despite a lack of proline residues. Inclusion of proline is a common strategy to stabilize turn structures but limits the design space for $\mathrm{CP}$ development. ${ }^{80}$ 
While the scoring function derived from cyclo- $\left(\mathrm{X}_{1} \mathrm{X}_{2} \mathrm{AAA}\right)$ enabled us to design wellstructured CPs that adopt the $\beta_{I I}+a_{R}$ turn combination, the distribution of the scores shows that most sequences are likely not well-structured (Figure 5B). Furthermore, the scores for the other turn combinations (such as $\beta_{\mathrm{I}}+\mathrm{a}_{\mathrm{R}}$ ) are all minimal, suggesting that it would be extremely unlikely to favor these conformations using simple sequence substitutions. For example, cyclo-(AFDAG) has the highest score to adopt $\beta_{\mathrm{I}}+\mathrm{a}_{\mathrm{R}}$, with the type I $\beta$-turn at ${ }^{1} \mathrm{AF}^{2}$ and the tight $\alpha_{\mathrm{R}}$ turn at $\mathrm{A}^{4}$. However, this score is only 0.208. BE-META simulation of cyclo-(AFDAG) shows that indeed the top cluster of this $\mathrm{CP}$ was $\beta_{\mathrm{I}}+a_{\mathrm{R}}$, however, with a population of $<30 \%$. Therefore, to design well-structured cyclic pentapeptides that adopt conformations other than the $\beta_{I^{\prime}}+\alpha_{R}$ turn combination demonstrated here, non-natural amino acids are likely needed. $\mathrm{D}$-amino acids are a logical choice, though incorporating other non-natural amino acids, such as $N$-methylated amino acids, $\beta$-amino acids and proline analogs may also prove to be useful tools for $\mathrm{CP}$ design. The effects of incorporating these non-natural amino acids are currently being investigated.

Having a simulation method which exploits the essential transitional motions of CPs has allowed us to efficiently simulate more than 70 head-to-tail cyclized pentapeptides and thereby better understand their sequence-structure relationships. We demonstrated the value of these data by using them to rationally design a $\mathrm{CP}$ with a high degree of structure in water. This method is not limited to cyclic pentapeptides or head-to-tail cyclized peptides, and can be readily extended to larger systems or macrocycles cyclized by other linking chemistries. This work is a clear demonstration of how rigorous, explicit-solvent simulation methods are opening new opportunities to rationally design CPs with desired structures, providing a platform to rationally design novel CPs.

\section{Supplementary Material}

Refer to Web version on PubMed Central for supplementary material.

\section{Acknowledgments}

We thank the support of the Tufts start-up fund, the Knez Family Faculty Investment Fund, and the National Institute of General Medical Sciences of the National Institutes of Health under award number R01GM124160 for Y.-S. L, Sontag Foundation Distinguished Scientist Award to B. L. P., and the National Science Foundation under Grant No. (1507456) for J. A. K. The content is solely the responsibility of the authors and does not necessarily represent the official views of the National Institutes of Health. We thank Dr. Kamlesh Makwana for assistance with NMR data acquisition and interpretation.

\section{References}

1. Sánchez-Quesada J, Kim HS, Ghadiri MR. A Synthetic Pore-Mediated Transmembrane Transport of Glutamic Acid. Angew Chem Int Ed. 2001; 40:2503-2506.

2. Brea RJ, Castedo L, Granja JR, Herranz MA, Sanchez L, Martin N, Seitz W, Guldi DM. Electron Transfer in Me-Blocked Heterodimeric a, $\gamma$-Peptide Nanotubular Donor-Acceptor Hybrids. Proc Natl Acad Sci US A. 2007; 104:5291-5294.

3. Hourani R, Zhang C, van der Weegen R, Ruiz L, Li C, Keten S, Helms BA, Xu T. Processable Cyclic Peptide Nanotubes with Tunable Interiors. J Am Chem Soc. 2011; 133:15296-15299. [PubMed: 21894889] 
4. Xiong JP, Stehle T, Zhang R, Joachimiak A, Frech M, Goodman SL, Arnaout MA. Crystal Structure of the Extracellular Segment of Integrin $a_{\mathrm{v}} \beta_{3}$ in Complex with an Arg-Gly-Asp Ligand. Science. 2002; 296:151-155. [PubMed: 11884718]

5. Horswill AR, Benkovic SJ. Cyclic Peptides, A Chemical Genetics Tool for Biologists. Cell Cycle. 2005; 4:552-555. [PubMed: 15876867]

6. Demmer O, Frank AO, Hagn F, Schottelius M, Marinelli L, Cosconati S, Brack-Werner R, Kremb S, Wester HJ, Kessler H. A Conformationally Frozen Peptoid Boosts CXCR4 Affinity and Anti-HIV Activity. Angew Chem Int Ed. 2012; 51:8110-8113.

7. Joo SH. Cyclic Peptides as Therapeutic Agents and Biochemical Tools. Biomol Ther. 2012; 20:1926.

8. Miranda E, Nordgren IK, Male AL, Lawrence CE, Hoakwie F, Cuda F, Court W, Fox KR, Townsend PA, Packham GK, et al. A Cyclic Peptide Inhibitor of HIF-1 Heterodimerization That Inhibits Hypoxia Signaling in Cancer Cells. J Am Chem Soc. 2013; 135:10418-10425. [PubMed: 23796364]

9. Kling A, Lukat P, Almeida DV, Bauer A, Fontaine E, Sordello S, Zaburannyi N, Herrmann J, Wenzel SC, Konig C, et al. Targeting DnaN for Tuberculosis Therapy using Novel Griselimycins. Science. 2015; 348:1106-1112. [PubMed: 26045430]

10. Morse RP, Willett JLE, Johnson PM, Zheng J, Credali A, Iniguez A, Nowick JS, Hayes CS, Goulding CW. Diversification of $\beta$-Augmentation Interactions Between CDI Toxin/Immunity Proteins. J Mol Biol. 2015; 427:3766-3784. [PubMed: 26449640]

11. Tapeinou A, Matsoukas MT, Simal C, Tselios T. Cyclic Peptides on a Merry-Go-Round: Towards Drug Design. Biopolymers. 2015; 104:453-461. [PubMed: 25968458]

12. Cardote TAF, Ciulli A. Cyclic and Macrocyclic Peptides as Chemical Tools To Recognise Protein Surfaces and Probe Protein-Protein Interactions. ChemMedChem. 2016; 11:787-794. [PubMed: 26563831]

13. Ryan DP, Matthews JM. Protein-Protein Interactions in Human Disease. Curr Opin Struct Biol. 2005; 15:441-446. [PubMed: 15993577]

14. Gonzalez MW, Kann MG. Chapter 4: Protein Interactions and Disease. PLoS Comput Biol. 2012; 8:e1002819. [PubMed: 23300410]

15. Arkin MR, Tang YY, Wells JA. Small-Molecule Inhibitors of Protein-Protein Interactions: Progressing toward the Reality. Chem Biol. 2014; 21:1102-1114. [PubMed: 25237857]

16. Milroy LG, Grossmann TN, Hennig S, Brunsveld L, Ottmann C. Modulators of Protein-Protein Interactions. Chem Rev. 2014; 114:4695-4748. [PubMed: 24735440]

17. Kopple KD, Go A, Logan RJJ, Savrda J. Conformations of Cyclic Peptides. VI. Factors Influencing Mono-, 1,4-Di-, and 1,2,4-Trisubstituted Cyclic Hexapeptide Backbones. J Am Chem Soc. 1972; 94:973-981. [PubMed: 5061144]

18. Tonelli AE, Brewster AI. Conformational Characteristics in Solution of the Cyclic Hexapeptide Gly-Gly-D-Ala-D-Ala-Gly-Gly. J Am Chem Soc. 1972; 94:2851-2854. [PubMed: 5017422]

19. Kopple KD, Go A, Schamper TJ. Conformation of Cyclic Peptides. 10. Conformational Averaging in Peptides with the Sequence Cyclo (Gly-D-Xxx-L-Yyy)2. J Am Chem Soc. 1978; 100:4289_ 4295.

20. Blout ER. Cyclic Peptides: Past, Present, and Future. Biopolymers. 1981; 20:1901-1912.

21. Varughese KI, Kartha G, Kopple KD. Crystal Structure and Conformation of Cyclo-(Glycyl-DLeucyl-L-Leucyl) 2 . J Am Chem Soc. 1981; 103:3310-3313.

22. Yang CH, Brown JN, Kopple KD. Crystal Structure and Solution Studies of the Molecular Conformation of the Cyclic Hexapeptide Cyclo-(Gly-L-His-Gly-L-Ala-L-Tyr-Gly). J Am Chem Soc. 1981; 103:1715-1719.

23. Kopple KD, Wang YS, Cheng AG, Bhandary KK. Conformations of Cyclic Octapeptides. 5. Crystal Structure of Cyclo(Cys-Gly-Pro-Phe $)_{2}$ and Rotating Frame Relaxation $\left(T_{1 \rho}\right)$ NMR Studies of Internal Mobility in Cyclic Octapeptides. J Am Chem Soc. 1988; 110:4168-4176.

24. Stradley SJ, Rizo J, Bruch MD, Stroup AN, Gierasch LM. Cyclic Pentapeptides as Models for Reverse Turns: Determination of the Equilibrium Distribution Between Type I and Type II Conformations of Pro-Asn and Pro-Ala $\beta$-turns. Biopolymers. 1990; 29:263-287. [PubMed: 2328290] 
25. Alberg DG, Schreiber SL. Structure-Based Design of a Cyclophilin-Calcineurin Bridging Ligand. Science. 1993; 262:248-250. [PubMed: 8211144]

26. Kopple KD, Bean JW, Bhandary KK, Briand J, D'Ambrosio CA, Peishoff CE. Conformational Mobility in Cyclic Oligopeptides. Biopolymers. 1993; 33:1093-1099. [PubMed: 8102073]

27. MarshallGR, , BeusenDD, , NikiforovichGV. Peptides: Synthesis, Structures, and ApplicationsGutteB, editorVol. 27. Academic Press, Inc; San Diego, CA: 1995193245

28. Beck JG, Chatterjee J, Laufer B, Kiran MU, Frank AO, Neubauer S, Ovadia O, Greenberg S, Gilon C, Hoffman A, et al. Intestinal Permeability of Cyclic Peptides: Common Key Backbone Motifs Identified. J Am Chem Soc. 2012; 134:12125-12133. [PubMed: 22737969]

29. Bhowmick A, Brookes DH, Yost SR, Dyson HJ, Forman-Kay JD, Gunter D, Head-Gordon M, Hura GL, Pande VS, Wemmer DE, et al. Finding Our Way in the Dark Proteome. J Am Chem Soc. 2016; 138:9730-9742. [PubMed: 27387657]

30. Brookes DH, Head-Gordon T. Experimental Inferential Structure Determination of Ensembles for Intrinsically Disordered Proteins. J Am Chem Soc. 2016; 138:4530-4538. [PubMed: 26967199]

31. Best RB. Computational and Theoretical Advances in Studies of Intrinsically Disordered Proteins. Curr Opin Struct Biol. 2017; 42:147-154. [PubMed: 28259050]

32. Bonomi M, Heller GT, Camilloni C, Vendruscolo M. Principles of Protein Structural Ensemble Determination. Curr Opin Struct Biol. 2017; 42:106-116. [PubMed: 28063280]

33. Riemann RN, Zacharias M. Reversible Scaling of Dihedral Angle Barriers During Molecular Dynamics to Improve Structure Prediction of Cyclic Peptides. J Pept Res. 2004; 63:354-364. [PubMed: 15102053]

34. Spitaleri A, Ghitti M, Mari S, Alberici L, Traversari C, Rizzardi GP, Musco G. Use of Metadynamics in the Design of isoDGR-Based $\alpha_{v} \beta_{3}$ Antagonists To Fine-Tune the Conformational Ensemble. Angew Chem Int Ed. 2011; 50:1832-1836.

35. Voelz VA, Dill KA, Chorny I. Peptoid Conformational Free Energy Landscapes From ImplicitSolvent Molecular Simulations in AMBER. Biopolymers. 2011; 96:639-650. [PubMed: 21184487]

36. Butterfoss GL, Yoo B, Jaworski JN, Chorny I, Dill KA, Zuckermann RN, Bonneau R, Kirshenbaum K, Voelz VA. De Novo Structure Prediction and Experimental Characterization of Folded Peptoid Oligomers. Proc Natl Acad Sci US A. 2012; 109:14320-14325.

37. Chen Y, Deng K, Qiu X, Wang C. Visualizing Cyclic Peptide Hydration at the Single-Molecule Level. Sci Rep. 2013; 3:2461. [PubMed: 23955234]

38. Damas JM, Filipe LCS, Campos SRR, Lousa D, Victor BL, Baptista AM, Soares CM. Predicting the Thermodynamics and Kinetics of Helix Formation in a Cyclic Peptide Model. J Chem Theory Comput. 2013; 9:5148-5157. [PubMed: 26583424]

39. Oakley MT, Johnston RL. Exploring the Energy Landscapes of Cyclic Tetrapeptides with Discrete Path Sampling. J Chem Theory Comput. 2013; 9:650-657. [PubMed: 23596359]

40. Oakley MT, Oheix E, Peacock AFA, Johnston RL. Computational and Experimental Investigations into the Conformations of Cyclic Tetra-a/ $\beta$-Peptides. J Phys Chem B. 2013; 117:8122-8134. [PubMed: 23758504]

41. Merten C, Li F, Bravo-Rodriguez K, Sanchez-Garcia E, Xu Y, Sander W. Solvent-Induced Conformational Changes in Cyclic Peptides: A Vibrational Circular Dichroism Study. Phys Chem Chem Phys. 2014; 16:5627-5633. [PubMed: 24513908]

42. Quartararo JS, Eshelman MR, Peraro L, Yu H, Baleja JD, Lin YS, Kritzer JA. A Bicyclic Peptide Scaffold Promotes Phosphotyrosine Mimicry and Cellular Uptake. Bioorg Med Chem. 2014; 22:6387-6391. [PubMed: 25438762]

43. Razavi AM, Wuest WM, Voelz VA. Computational Screening and Selection of Cyclic Peptide Hairpin Mimetics by Molecular Simulation and Kinetic Network Models. J Chem Inf Model. 2014; 54:1425-1432. [PubMed: 24754484]

44. Paissoni C, Ghitti M, Belvisi L, Spitaleri A, Musco G. Metadynamics Simulations Rationalise the Conformational Effects Induced by $N$-Methylation of RGD Cyclic Hexapeptides. Chem Eur J. 2015; 21:14165-14170. [PubMed: 26248541]

45. Wakefield AE, Wuest WM, Voelz VA. Molecular Simulation of Conformational Pre-Organization in Cyclic RGD Peptides. J Chem Inf Model. 2015; 55:806-813. [PubMed: 25741627] 
46. Yedvabny E, Nerenberg PS, So C, Head-Gordon T. Disordered Structural Ensembles of Vasopressin and Oxytocin and Their Mutants. J Phys Chem B. 2015; 119:896-905. [PubMed: 25231121]

47. Yu H, Lin YS. Toward Structure Prediction of Cyclic Peptides. Phys Chem Chem Phys. 2015; 17:4210-4219. [PubMed: 25566700]

48. Geng H, Jiang F, Wu YD. Accurate Structure Prediction and Conformational Analysis of Cyclic Peptides with Residue-Specific Force Fields. J Phys Chem Lett. 2016; 7:1805-1810. [PubMed: 27128113]

49. McHugh SM, Rogers JR, Yu H, Lin YS. Insights Into How Cyclic Peptides Switch Conformations. J Chem Theory Comput. 2016; 12:2480-2488. [PubMed: 27031286]

50. McHugh SM, Yu H, Slough DP, Lin YS. Mapping the Sequence-Structure Relationships of Simple Cyclic Hexapeptides. Phys Chem Chem Phys. 2017; 19:3315-3324. [PubMed: 28091629]

51. Slough DP, Yu H, McHugh SM, Lin YS. Towards Accurately Modeling N-Methylated Cyclic Peptides. Phys Chem Chem Phys. 2017; 19:5377-5388. [PubMed: 28155950]

52. Pettersen EF, Goddard TD, Huang CC, Couch GS, Greenblatt DM, Meng EC, Ferrin TE. UCSF Chimera-A Visualization System for Exploratory Research and Analysis. J Comput Chem. 2004; 25:1605-1612. [PubMed: 15264254]

53. Bussi G, Donadio D, Parrinello M. Canonical Sampling Through Velocity Rescaling. J Chem Phys. 2007; 126:014101. [PubMed: 17212484]

54. Cheng A, Merz KM Jr. Application of the Nosé Hoover Chain Algorithm to the Study of Protein Dynamics. J Phys Chem. 1996; 100:1927-1937.

55. Lingenheil M, Denschlag R, Reichold R, Tavan P. The "Hot-Solvent/Cold-Solute" Problem Revisited. J Chem Theory Comput. 2008; 4:1293-1306. [PubMed: 26631705]

56. Berendsen HJC, Postma JPM, van Gunsteren WF, DiNola A, Haak JR. Molecular Dynamics with Coupling to an External Bath. J Chem Phys. 1984; 81:3684-3690.

57. Hess B, Bekker H, Berendsen HJC, Fraaije JGEM. LINCS: A Linear Constraint Solver for Molecular Simulations. J Comput Chem. 1997; 18:1463-1472.

58. Hockney RW. The Potential Calculation and Some Applications. Methods Comput Phys. 1970; 9:135-211.

59. Essmann U, Perera L, Berkowitz ML, Darden T, Lee H, Pedersen LG. A Smooth Particle Mesh Ewald Method. J Chem Phys. 1995; 103:8577-8593.

60. AllenMP, , TildesleyDJ, editorsComputer Simulations of LiquidsOxford University Press; New York: 1987

61. Zhou CY, Jiang F, Wu YD. Residue-Specific Force Field Based on Protein Coil Library. RSFF2: Modification of AMBER ff99SB. J Phys Chem B. 2015; 119:1035-1047. [PubMed: 25358113]

62. Jorgensen WL, Chandrasekhar J, Madura JD, Impey RW, Klein ML. Comparison of Simple Potential Functions for Simulating Liquid Water. J Chem Phys. 1983; 79:926-935.

63. Hess B, Kutzner C, Van Der Spoel D, Lindahl E. GROMACS 4: Algorithms for Highly Efficient, Load-Balanced, and Scalable Molecular Simulation. J Chem Theory Comput. 2008; 4:435-447. [PubMed: 26620784]

64. Tribello GA, Bonomi M, Branduardi D, Camilloni C, Bussi G. PLUMED 2: New Feathers for an Old Bird. Comput Phys Commun. 2014; 185:604-613.

65. Mu Y, Nguyen PH, Stock G. Energy Landscape of a Small Peptide Revealed by Dihedral Angle Principal Component Analysis. Proteins. 2005; 58:45-52. [PubMed: 15521057]

66. Sittel F, Jain A, Stock G. Principal Component Analysis of Molecular Dynamics: On the Use of Cartesian vs. Internal Coordinates. J Chem Phys. 2014; 141:014111. [PubMed: 25005281]

67. Rodriguez A, Laio A. Clustering by Fast Search and Find of Density Peaks. Science. 2014; 344:1492-1496. [PubMed: 24970081]

68. King BM, Tidor B. MIST: Maximum Information Spanning Trees for Dimension Reduction of Biological Data Sets. Bioinformatics. 2009; 25:1165-1172. [PubMed: 19261718]

69. King BM, Silver NW, Tidor B. Efficient Calculation of Molecular Configurational Entropies Using an Information Theoretic Approximation. J Phys Chem B. 2012; 116:2891-2904. [PubMed: 22229789] 
70. Fleck M, Polyansky AA, Zagrovic B. PARENT: A Parallel Software Suite for the Calculation of Configurational Entropy in Biomolecular Systems. J Chem Theory Comput. 2016; 12:2055-2065. [PubMed: 26989950]

71. Mijalis AJ, Thomas DA 3rd, Simon MD, Adamo A, Beaumont R, Jensen KF, Pentelute BL. A Fully Automated Flow-Based Approach for Accelerated Peptide Synthesis. Nat Chem Biol. 2017; 13:464-466. [PubMed: 28244989]

72. Karle IL. Crystal Structure and Conformation of Cyclo-(GlycylProlylGlycyl-D-AlanylProlyl) Containing $4 \rightarrow 1$ and $3 \rightarrow 1$ Intramolecular Hydrogen Bonds. J Am Chem Soc. 1978; 100:12861289.

73. Gurrath M, Mullen G, Kessler H, Aumailley M, Timpl R. Conformation/Activity Studies of Rationally Designed Potent Anti-Adhesive RGD Peptides. Eur J Biochem. 1992; 210:911-921. [PubMed: 1483474]

74. Mierke DF, Kurz M, Kessler H. Peptide Flexibility and Calculations of an Ensemble of Molecules. J Am Chem Soc. 1994; 116:1042-1049.

75. Nagarajaram HA, Ramakrishnan C. Stereochemical Studies on Cyclic Peptides: Detailed Energy Minimization Studies on Hydrogen Bonded All-Trans Cyclic Pentapeptide Backbones. J Bioscience. 1995; 20:591-611.

76. DaviesJS. Cyclic PolymersSemlyenER, editorKluwer Academic Publishers; Netherlands: 200085124

77. Nikiforovich GV, Kover KE, Zhang WJ, Marshall GR. Cyclopentapeptides as Flexible Conformational Templates. J Am Chem Soc. 2000; 122:3262-3273.

78. Zhang X, Nikiforovich GV, Marshall GR. Conformational Templates for Rational Drug Design: Flexibility of Cyclo(D-Pro 1 -Ala 2 -Ala 3 -Ala 4 -Ala 5 ) in DMSO Solution. J Med Chem. 2007; 50:2921-2925. [PubMed: 17497764]

79. DemmerO, , FrankAO, , KesslerH. Peptide and Protein Design for Biopharmaceutical ApplicationsJensenKJ, editorJohn Wiley \& Sons, Ltd; Chichester, UK: 2009133176

80. Hosseinzadeh P, Bhardwaj G, Mulligan VK, Shortridge MD, Craven TW, Pardo-Avila F, Rettie SA, Kim DE, Silva DA, Ibrahim YM, et al. Comprehensive Computational Design of Ordered Peptide Macrocycles. Science. 2017; 358:1461-1466. [PubMed: 29242347] 
(A)
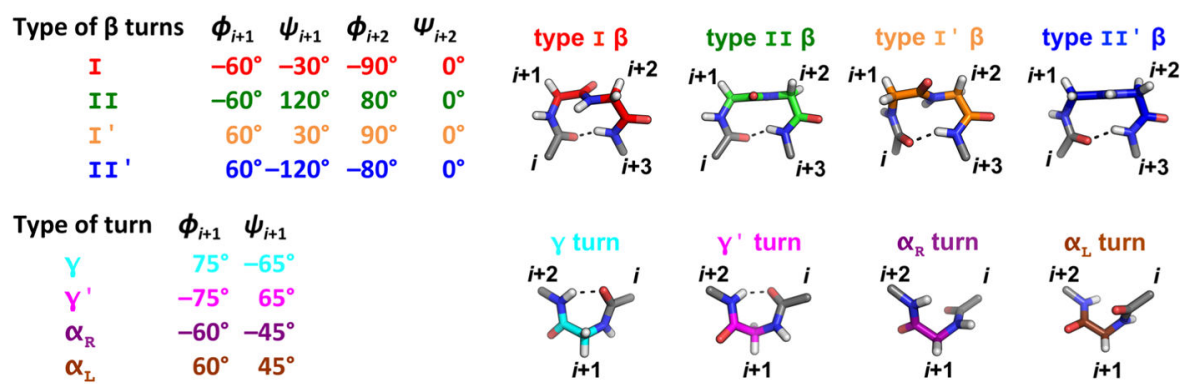

(B)
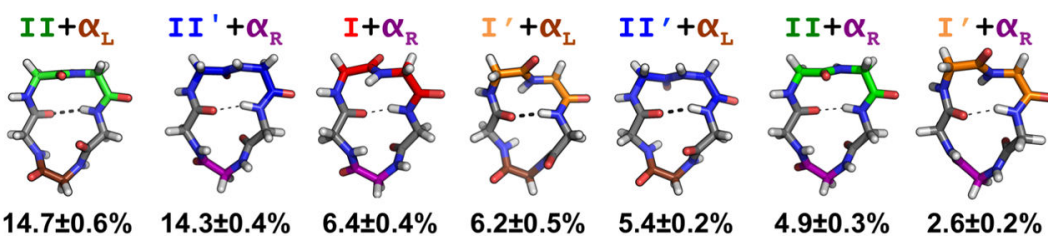

$I+\alpha_{I}$

$14.7 \pm 0.6 \%$

$14.3 \pm 0.4 \%$

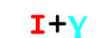

$I^{\prime}+Y^{\prime}$

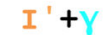

$4.9 \pm 0.3 \%$

$2.6 \pm 0.2 \%$
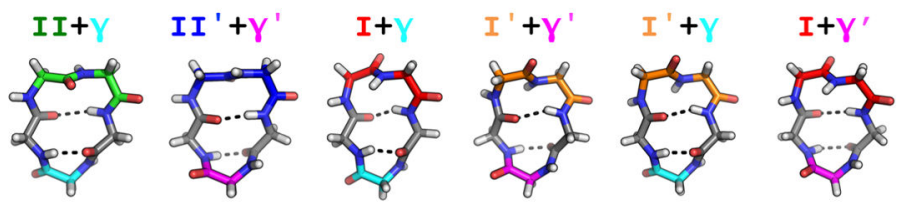

II ' $+\gamma$

$I I+Y^{\prime}$

$1.3 \pm 0.2 \%$

$1.3 \pm 0.2 \%$

$1.1 \pm 0.1 \%$

$1.0 \pm 0.1 \% \quad 0.73 \pm 0.03 \%$

$0.65 \pm 0.1 \%$
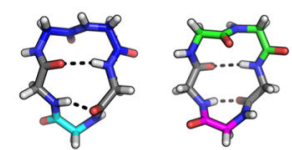

Figure 1.

Cyclic pentapeptides typically form a $\beta$-turn plus a tight $\gamma / \gamma^{\prime}$ or $a_{R} / a_{L}$ turn opposite the $\beta$ turn. (A) Ideal dihedral angles, representative structures and hydrogen bond patterns for the four types of $\beta$-turns and four types of tight turns. (B) Populations and representative structures for the 16 turn types from our BE-META simulations of cyclo-(GGGGG). Type I, $\mathrm{I}^{\prime}$, II and II $\beta$-turns are shown in red, orange, green and blue, respectively. Tight turns $\gamma, \gamma$ ', $a_{R}$ and $a_{L}$ are shown in cyan, magenta, purple and brown, respectively. Populations and standard deviation were calculated from the five neutral replicas of the S1 simulations. 


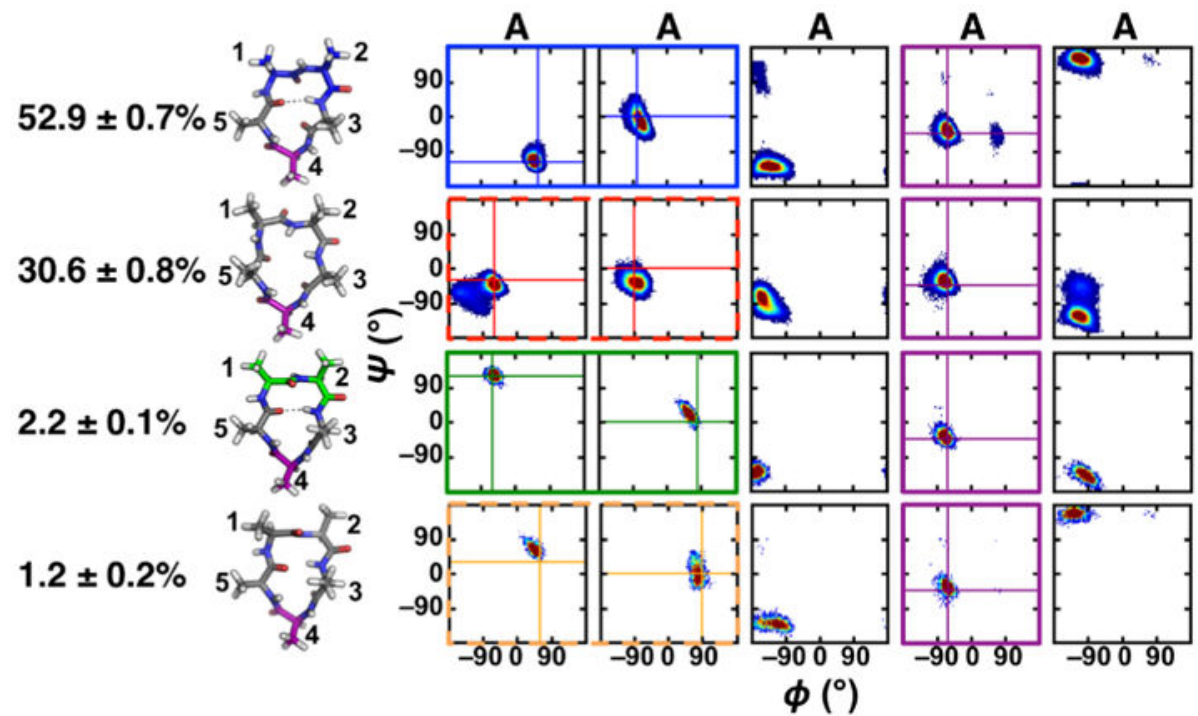

Figure 2.

Populations, representative structures and Ramachandran plots for the top four clusters of cyclo-(AAAAA). Type II $\beta$, type II' $\beta$ and $\alpha_{R}$ turns are shown and boxed in the

Ramachandran plots in green, blue and purple, respectively. Distorted type I and I ' $\beta$-turns are boxed in the Ramachandran plots by red and orange dashed lines, respectively.

Populations and standard deviation were calculated from the five neutral replicas of the S1 simulation. 
(A)

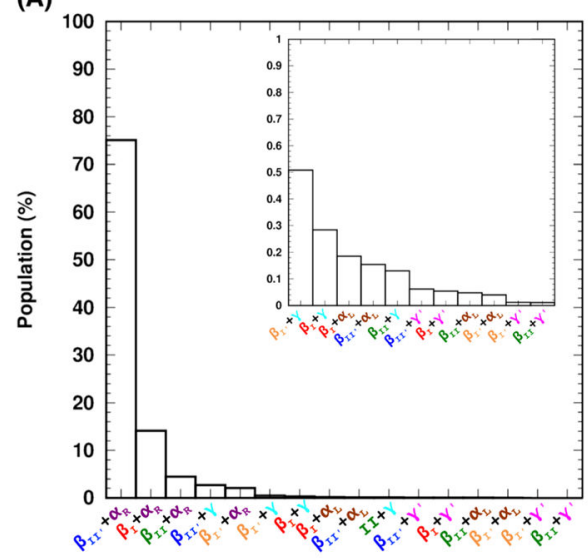

(B)

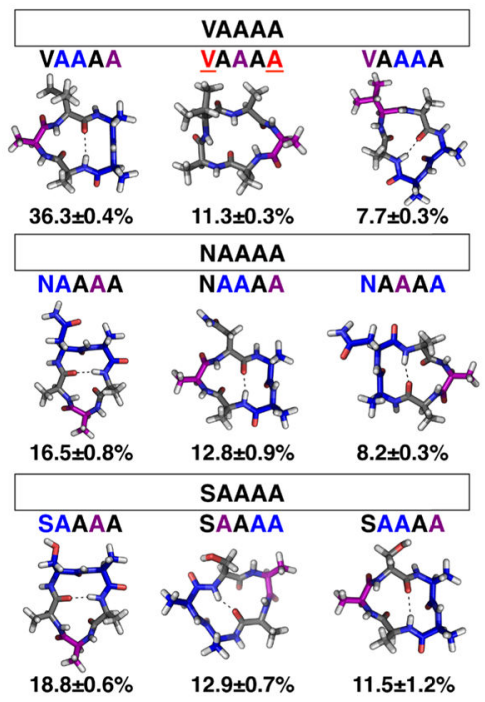

Figure 3.

(A) Populations of 16 turn combinations from simulations of cyclo-( $\left.\mathrm{X}_{1} \mathrm{AAAA}\right)$. Results use the cut-off turn analysis (see Materials and Methods for analysis details). (B) Populations and representative structures of the three most populated clusters of cyclo-(VAAAA), cyclo(NAAAA) and cyclo-(SAAAA). Type $\mathrm{II}^{\prime} \beta$-turn and $\mathrm{a}_{\mathrm{R}}$ turn are shown and their locations in the sequences highlighted in blue and purple, respectively. The location of distorted type I $\beta$-turn in the sequence is highlighted in red and underlined. Populations and standard deviation were calculated from the five neutral replicas of the S1 simulations. 
(A)

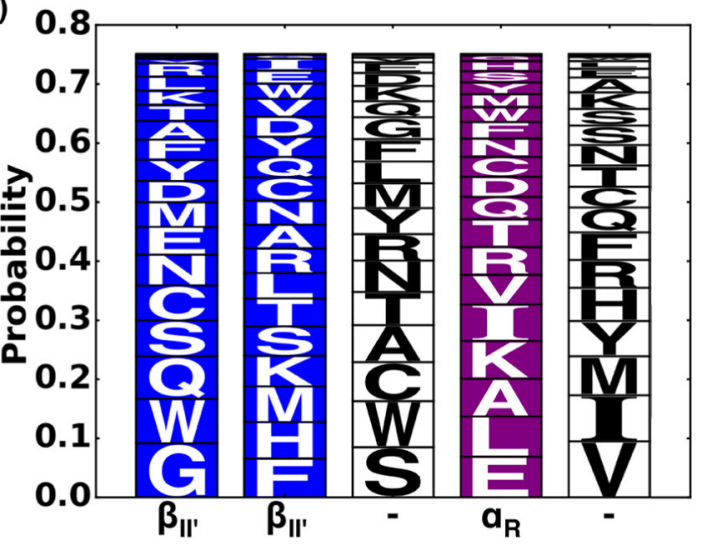

(B)

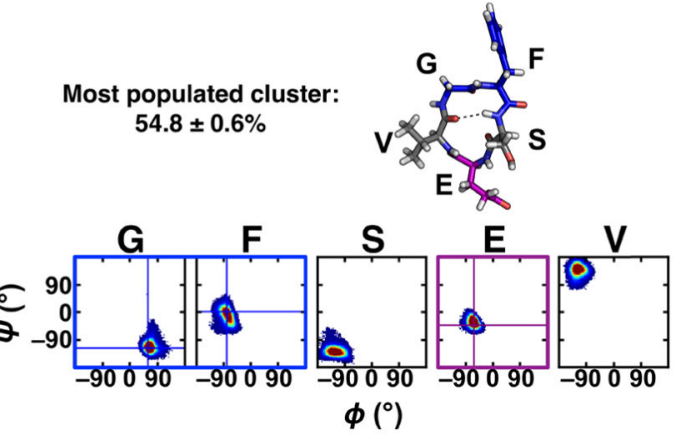

Figure 4.

(A) Logo plot for cyclo-( $\mathrm{X}_{1}$ AAAA) with the $\beta_{\mathrm{II}}{ }+\mathrm{a}_{\mathrm{R}}$ turn combination. Results use cut- off turn analysis of the $\mathrm{S} 1$ simulations (see Materials and Methods for analysis details). Type II' $\beta$-turn and $a_{R}$ turn are shown and their locations in the sequences highlighted in blue and purple, respectively. (B) Population, representative structure and Ramachandran plot for the most populated cluster of cyclo-(GFSEV). Type II' $\beta$-turn and $a_{\mathrm{R}}$ turn are shown in blue and purple boxes, respectively. Population and standard deviation was calculated from the five neutral replicas of the $\mathrm{S} 1$ simulation. 
(A)

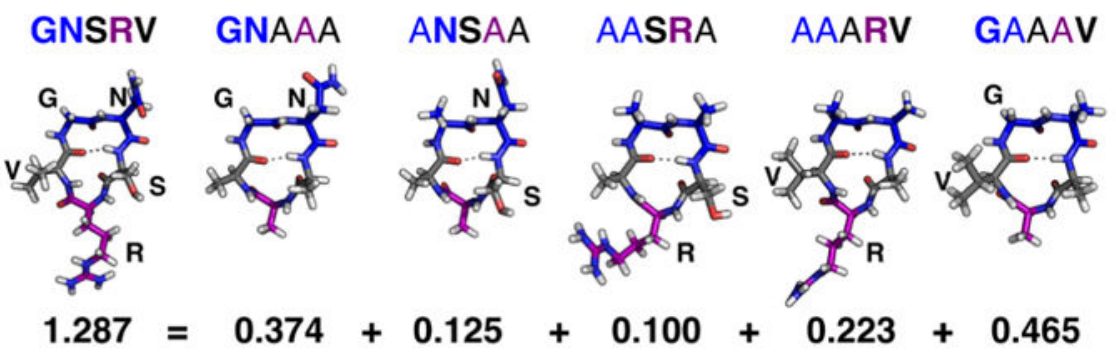

(B)

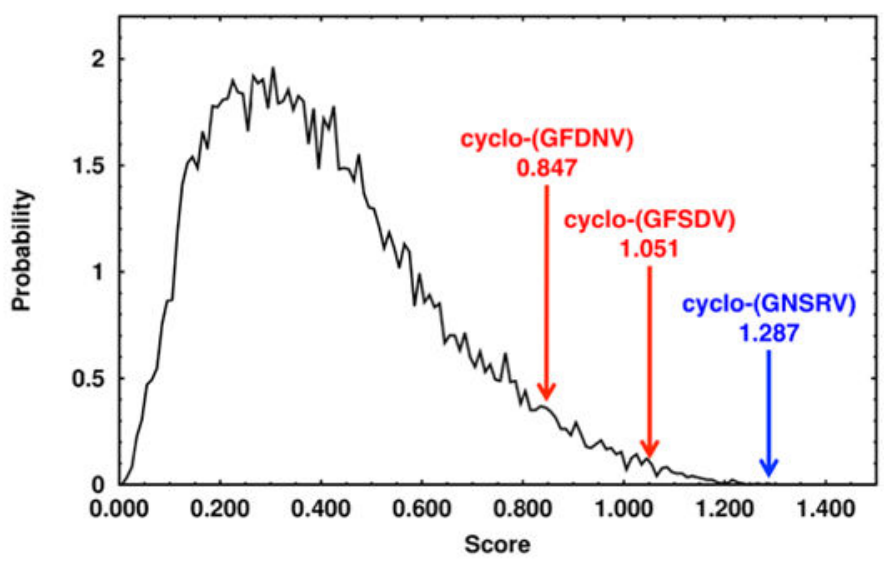

Figure 5.

Cyclo-(GNSRV) was predicted to have high preference to adopt a $\beta_{I I^{\prime}}+a_{R}$ turn combination based on neighbor pair scoring. (A) (Top) $\beta_{\mathrm{II}}{ }^{\prime}+a_{\mathrm{R}}$ turn combination for cyclo-(GNSRV) and its five parent sequences: cyclo-(GNAAA), cyclo-(ANSAA), cyclo-(AASRA), cyclo-

(AAARV) and cyclo-(GAAAV). Neighbor pairs are bolded, and type II $^{\prime} \beta$-turn and tight turn $a_{R}$ are shown in blue and purple, respectively. (Bottom) Neighbor scores, which were calculated from using cut-off analysis for the corresponding $\beta_{I I^{\prime}}+a_{R}$ turn combination. (B) Distribution of scores for the $\beta_{\mathrm{II}}+\mathrm{a}_{\mathrm{R}}$ turn combination for the 16,807 sequences of cyclo$\left(\mathrm{X}_{1} \mathrm{X}_{2} \mathrm{X}_{3} \mathrm{X}_{4} \mathrm{X}_{5}\right)$, where $\mathrm{X}_{1} / \mathrm{X}_{2} / \mathrm{X}_{3} / \mathrm{X}_{4} / \mathrm{X}_{5}$ were $\mathrm{G}, \mathrm{V}, \mathrm{F}, \mathrm{R}, \mathrm{D}, \mathrm{N}$ or $\mathrm{S}$. Well-structured CP cyclo-(GNSRV) and its score is highlighted in blue. Cyclo-(GFSDV), the proxy of cyclo(GFSEV), from simulations of cyclo-( $\left.\mathrm{X}_{1} \mathrm{AAAA}\right)$, and cyclo-(GFDNV) and their associated scores are highlighted in red. 


\section{(A) cyclo-(GNSRV)}

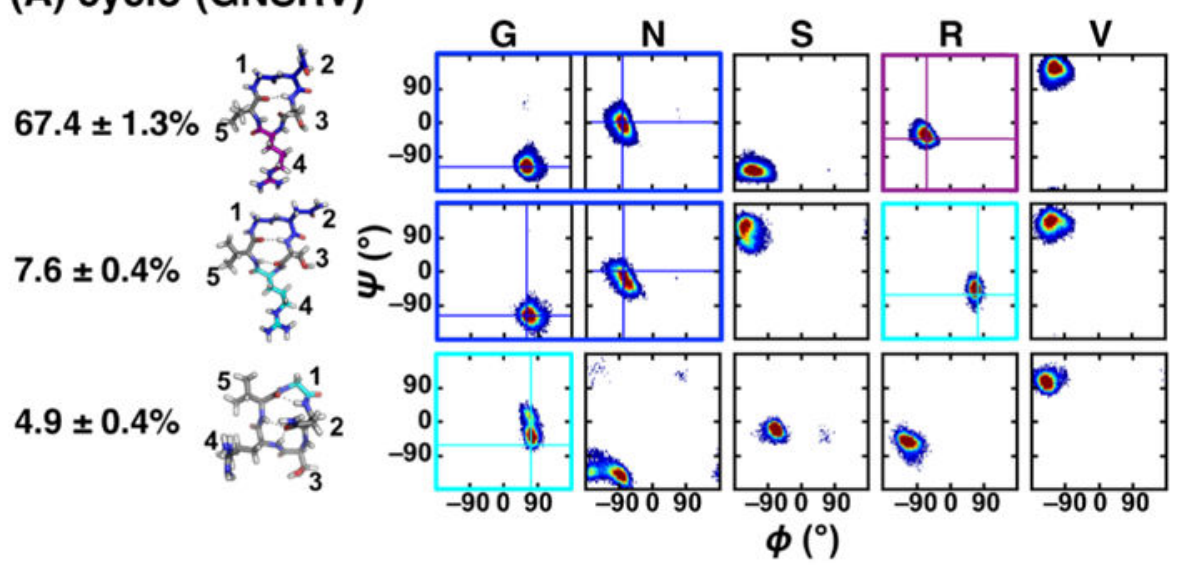

(B) cyclo-(GFDNV)

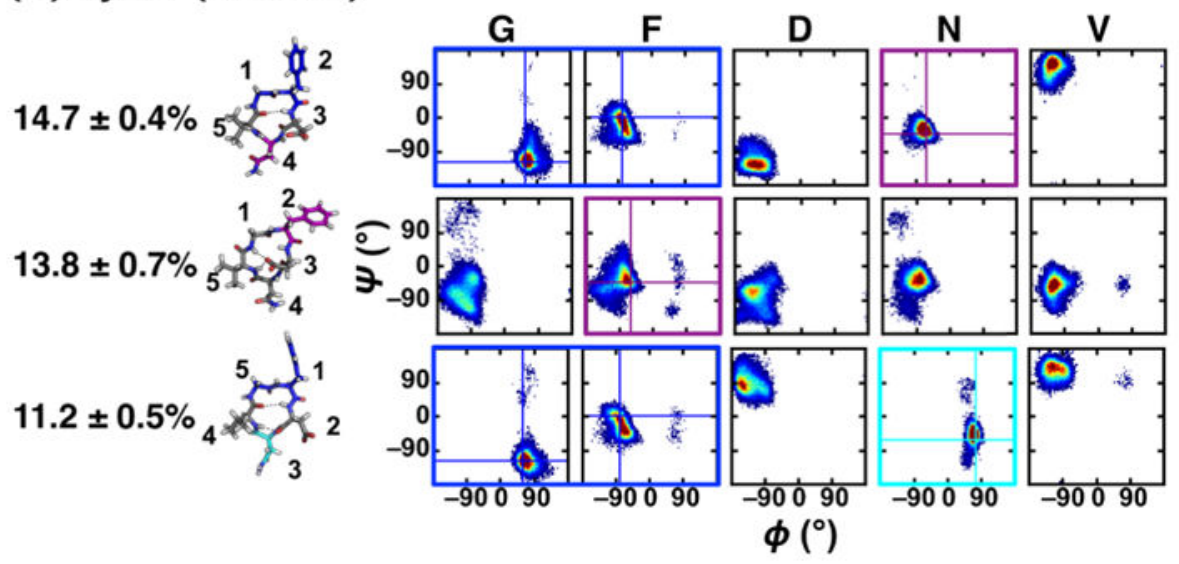

Figure 6.

Populations, representative structures and Ramachandran plots for the top three clusters of (A) cyclo-(GNSRV) and (B) cyclo-(GFDNV). Type II' $\beta$-turns are shown in blue boxes. Tight turns $\gamma$ and $\alpha_{R}$ are shown in cyan and purple boxes, respectively. Populations and standard deviation were calculated from the five neutral replicas of the $\mathrm{S} 1$ simulation. 


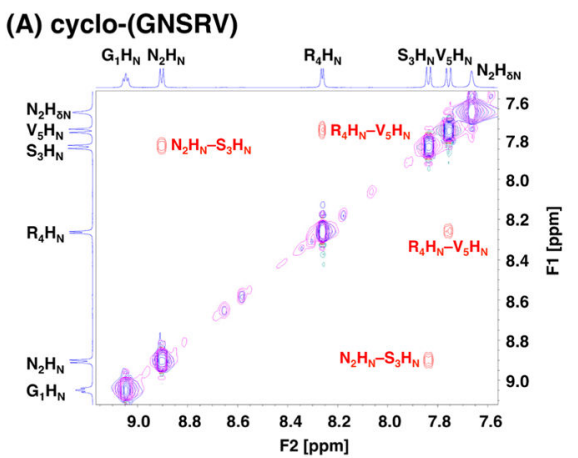

(B) cyclo-(GFDNV)

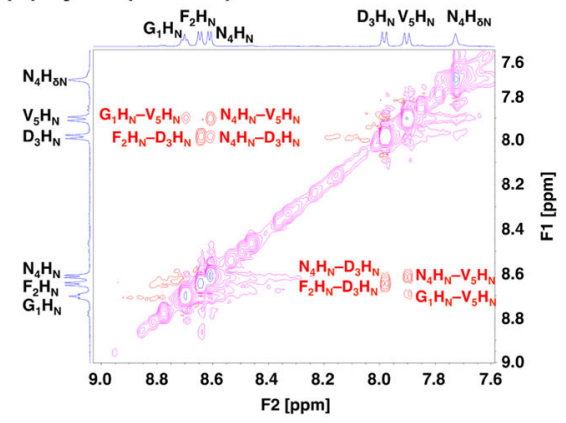

(C)

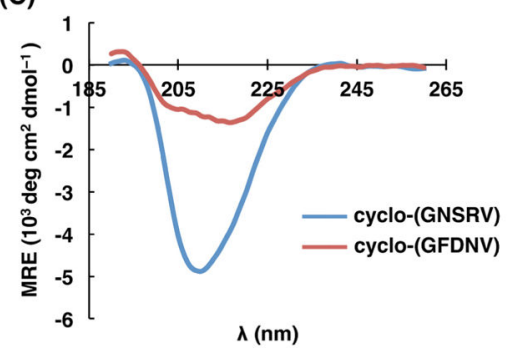

Figure 7.

Structural characterization of cyclo-(GNSRV) and cyclo-(GFDNV). (A) $\mathrm{H}_{\mathrm{N}}$ region of ROESY spectrum (red, magenta) for cyclo-(GNSRV). TOCSY spectrum (blue, cyan) is overlaid to highlight separate spin systems. Two ROESY cross-peaks were observed in this region, between $\mathrm{N}_{2} \mathrm{H}_{\mathrm{N}}$ and $\mathrm{S}_{3} \mathrm{H}_{\mathrm{N}}$ and between $\mathrm{R}_{4} \mathrm{H}_{\mathrm{N}}$ and $\mathrm{V}_{5} \mathrm{H}_{\mathrm{N}}$. (B) $\mathrm{H}_{\mathrm{N}}$ region of ROESY and TOCSY spectra for cyclo-(GFDNV). Four different ROESY $\mathrm{N}_{\mathrm{H}}-\mathrm{N}_{\mathrm{H}}$ cross-peaks were observed. (C) Circular dichroism spectra for both cyclic peptides at $87.5 \mu \mathrm{M}$ in aqueous solution at $20{ }^{\circ} \mathrm{C}$, plotted as mean residue ellipticity (MRE). 